\title{
Multiple Myeloma - Atypical Presentation - Clinicopathological Correlation
}

\author{
Emani Usha Bhargavi ${ }^{1}$, Vaddadi Suresh ${ }^{2}$ \\ ${ }^{1}$ Department of Pathology, GSL Medical College, Rajahmundry, Andhra Pradesh, India. \\ ${ }^{2}$ Department of Medicine, GSL Medical College, Rajahmundry, Andhra Pradesh, India.
}

\section{ABSTRACT}

\section{BACKGROUND}

Multiple myeloma, malignant neoplasm of plasma cells producing monoclonal para protein is one of the most common haematological malignancies we see in our routine practice. Multiple myeloma has varied and diverse clinical presentations, of which most common clinical features will be anaemia, bone pain, fever, fatigue, weight loss, paraesthesia, renal failure, pathological fractures, cutaneous lesions, etc. We hereby, present a series of multiple myeloma cases with unusual presentation over a period of 3 years. The purpose of the study was to evaluate the unusual and rare clinicohaematological presentation in patients with multiple myeloma.

\section{METHODS}

In this case series study, we reviewed bone marrow aspirate \& / or biopsy slides in our hospital from January 2017 to January 2020. Patients diagnosed with multiple myeloma were selected. Patients' clinical information, haematological and other findings were obtained from the medical records department and compiled, and correlation was done.

\section{RESULTS}

We came across a total of 9 cases of multiple myeloma with very unusual and rare clinical presentations. A thorough clinical, radiological, haematological, biochemical and histopathological correlation was done before giving a final diagnosis in these cases. Rare cutaneous and other involvement of multiple myeloma was noted.

\section{CONCLUSIONS}

Multiple myeloma is the most common malignancy with comparatively poor prognosis. However, early diagnosis of multiple myeloma always helps the clinician in improving the outcome and has been shown to have better prognosis. The present case series is an attempt to understand the clinico-pathological correlation, wide spectrum of clinical presentation and associated rarity of presentations.

\section{KEY WORDS}

Myeloma; Lytic Lesions; Bone Marrow
Corresponding Author: Dr. Emani Usha Bhargavi, Assistant Professor of Pathology, GSL Medical College, Rajahmundry, Andhra Pradesh, India.

E-mail: ushabhargavimani@gmail.com

DOI: $10.14260 / j e m d s / 2021 / 715$

How to Cite This Article:

Bhargavi EU, Suresh V. Multiple myelomaatypical presentation - clinicopathological correlation. J Evolution Med Dent Sci 2021;10(40):3526-3532, $10.14260 /$ jemds/2021/715

Submission 23-09-2020, Peer Review 20-01-2021, Acceptance 27-01-2021, Published 04-10-2021.

Copyright (C) 2021 Emani Usha Bhargavi et al. This is an open access article distributed under Creative Commons Attribution License [Attribution 4.0 International (CC BY 4.0)] 


\section{BACKGROUND}

Giving credence in 1837 by von Rustizky, $1,2,3$ multiple myeloma (MM) is categorised as a malignant disorder that targets haematological function in the human body. It presents as the unchecked proliferation of monoclonal / multicentric cells within the bone marrow \& is commonly cited as accounting for over $10 \%$ of malignancies attributed to the presence of haematological disease. ${ }^{4,5}$

The cells associated with multiple myeloma are split into 4 subtypes:

\section{- Mature.}

Immature.

Pleomorphic.

Plasmablastic.

Mature myeloma cells are characterized by their distinct round \& eccentric nucleus that presents without nucleoli in a cartwheel pattern. They have a perinuclear halo paired with copious basophilic cytoplasm. Immature myeloma cells are characterized by an irregular nucleus that has displaced chromatin paired with prominent nucleoli and a high nuclear cytoplasmic N / C ratio. Pleomorphic myeloma cells are characterized by, as the name suggests, a degree of nuclear pleomorphism with a poly-lobated nucleus paired with prominent nucleoli. Myeloma cell survival and subsequent spread can be directly attributed to clonal plasma cells interacting with stromal cells to release cytokines such as TNF $\alpha$ and IL-6 in the bone marrow. This also allows for the myeloma cells to produce receptor activator of nuclear factor kappa-B ligand (RANKL), an apoptosis regulator gene, that when bound to receptor activator of nuclear factor $\mathrm{k} B$ (RANK), receptors situated on osteoclasts, results in excess osteoclast activation. The upsurge in osteoclastic activity results in hypercalcemia, degradation of bony structures and eventually presentation of lytic bone lesions. The presentation of hypercalcemia is significant as the excess intra tubular calcium deposition along with increased paraprotein levels and amyloidosis often results in significant renal impairment and eventual failure.

The following diagnostic criteria, as set forth by the International Myeloma Working Group can be followed by a clinician to confirm suspicion of multiple myeloma:

Serum \& urine present with significant M-protein levels

Clonal plasma cell proliferation in bone marrow

Presentation of organ damage / failure

When the clinician is suspecting myeloma, the patient should be screened via serum free light chain (FLC) assay, ${ }^{6}$ serum protein electrophoresis and serum immunofixation in order to identify the presence of any $\mathrm{M}$ proteins which is characteristic of multiple myeloma. The common symptoms for the disorder are excess fatigue and bone pain. The presentation can also include instances of hypercalcemia, anaemia, lytic bone lesions, amyloidosis and hyper viscosity which can exacerbate into extensive skeletal destruction and infections that result in serious organ damage and subsequent failure. Plasmablastic myeloma cells are characterized by their overall large size, marked nuclear polymorphism and exhibit significant cellular atypia. Their presence is often seen as an indicator for poor prognosis. 7,8

Other clinical features of note are the presentation of pathological fractures, peripheral neuropathy, spinal compression, weight loss and extra medullary plasmacytomas.
It should also be noted that multiple myeloma patients have an increased risk of infection due to hypogammaglobulinemia paired with neutropenia., 9,10

However, it is quite possible for rare presentations of multiple myeloma that step outside the norm in regard to clinical feature. This particular case series is one such occurrence: A female presented with coagulation abnormality; a patient presented with soft tissue swelling. In this case series, we included cases of multiple myeloma with only rare and unusual findings over a period of 3 years.

\section{METHODS}

This is a case series study. In this study, we have reviewed bone marrow aspirate, biopsy slides and case records from medical records department in our hospital from Jan 2017 to Jan 2020. Patients diagnosed of multiple myeloma were selected and included in our study. The diagnosis of multiple myeloma was made based on the following parameters (as in WHO classification): $\geq 10 \%$ monoclonal plasma cells in bone marrow, monoclonal protein in serum and / urine, one or more myeloma related organ damage like hypercalcemia, anaemia, lytic bone lesions and kidney biopsy diagnosis of paraprotein associated lesion like amyloidosis, cast nephropathy. Patients' clinical information obtained from medical case records including the age, sex, location, clinical and other laboratory findings, i.e. complete blood counts, serum calcium, serum proteins, renal function test, $\mathrm{x}$-ray, ultrasound, serum protein electrophoresis, urinary Bence jones proteins along with bone marrow aspirate \& biopsy report with immunohistochemistry were obtained from the medical records department and correlation was done. All cases with unusual clinical presentation were only included in our study.

\section{RESULTS}

On review, a total of 34 cases of multiple myeloma were noticed and studied from the medical records, of whom 25 were males and 9 females (M: F: 2.7:1). The age of the patients ranged from 30 to 76 years with mean age being 55.34 years. The common presenting symptoms in most of the patients were found to be severe generalized weakness, fever, fatigability, lower limb weakness, bone pain and chronic backache.. Other less common presentations noted were decreased appetite, breathlessness may be due to anaemia, pedal oedema, generalized anasarca, altered sensorium, decreased urinary output, body aches and pathological fractures. We found a total of 9 cases of multiple myeloma with unusual and rare presentations.

\section{Case 1}

A 30-year-old female patient presented to gynaecology outpatient department (OPD) with menorrhagia, underwent complete blood counts, pap smear and endometrial curettage and ultra-sonogram. Complete blood counts show $\mathrm{Hb} 7 \mathrm{gm} \%$ and peripheral smear showed microcytic hypochromic anaemia (? due to chronic blood loss) ultra-sonogram of 
abdomen and pelvis revealed a bulky uterus with anterior wall fibroid, pap smear was reported as inflammatory smear and pre-operative endometrium biopsy showed no significant pathology. Patient also underwent preoperative blood transfusion and after which patient was posted for elective hysterectomy, surgery was uneventful, and histopathology reports also showed leiomyoma. The postoperative period was uneventful, and patient was discharged with haematinics treatment. When patient was reviewed after 1-month, severe breathlessness, fatigue ability, severe pallor, complete blood count (CBC) revealed haemoglobin hb to be $4 \mathrm{gm} \%$ and was referred to physician. B12 and folic acid were normal with decreased serum ferritin, diagnosed as refractory anaemia and was advised bone marrow which revealed plasma cells of 85 $\%$ (Image 1) and serum calcium was normal, skeletal survey showed no lytic lesions, Bence jones protein was not detected, serum electrophoresis showed M spike and immunofixation confirmed monoclonal proliferation.

\section{Case 2}

It is a very interesting case, young male, aged 32 years, who was suffering from bleeding per rectum consulted a surgeon. On examination, grade 3 haemorrhoids were noted, and surgical screening was done and posted for haemorrhoidectomy. On post-operative $4^{\text {th }}$ day, patient presented with high grade fever and chills and rashes on body, CBP revealed $\mathrm{Hb} 4 \mathrm{gm} \%$ with platelet count of 20,000, peripheral smear appeared normal and bone marrow examination was advised which showed $65 \%$ plasma cells, serum calcium was elevated, serum electrophoresis revealed M spike.

\section{Case 3}

35-year-old female presented to medical OPD for evaluation of fever, and routine investigations were advised. Pathologist received a call from the phlebotomist in sample collection room with unique complaint that the blood as soon as withdrawn from the patient is getting clotted even before putting sample in the specific anticoagulant tube, on examination, patient was febrile with no other positive findings, suspecting of thrombophilia or coagulation disorder, neither the clinician nor pathologist were left with no clues, even a finger prick smear was also getting clotted, sS left out with only option of bone marrow examination which revealed a scanty yield still could be able to make a smear showing marrow plasmacytosis of $88 \%$ and was referred to higher centres for further management.

\section{Case 4}

72-year-old male presented to pulmonology OPD with cough and breathlessness. On examination. a swelling was noted on the chest wall and was advised fine needle aspiration cytology) FNAC which revealed blood cellular elements and plasma cells and was advised TruCut biopsy and radiological correlation, $\mathrm{x}$ ray of chest showed a lytic lesion in rib with soft tissue extension, bone marrow was done which showed marrow plasmacytosis, serum calcium was normal, serum electrophoresis showed M spike.

\section{Case 5}

A 54-year-old male known diabetic patient for the last 20 years was referred to medical OPD by endocrinology department for treating refractory anaemia. Patient is known case of diabetic nephropathy with anaemia and was on erythropoietin injections for the last 6 months and haemoglobin is improved, for the last two months he had refractory anaemia and vitamin. B12, folic acid and iron studies were found to be normal, hence referred to physician where all other routine investigations were found to be normal, stool for occult blood, upper gastrointestinal (GI) endoscopy, lower GI endoscopy were found to be normal. Complete hemogram and peripheral smear revealed a normocytic normochromic anaemia of moderate degree, as being a case of refractory anaemia, bone marrow has been done and found to have plasma cells of $55 \%$, serum electrophoresis which revealed M spike and treated as case a multiple myeloma.

\section{Case 6}

This case is a very interesting case and though not included in the current study, in view of its rarity has been mentioned in this article. A 12-year-old presented with hepatomegaly and mild splenomegaly and anaemia, diagnosed as a case of hemoglobinopathy. Haemoglobin electrophoresis was done which was found to be normal, as child had history of recent blood transfusions done outside discharge and asked to review after 3 months for repeat $\mathrm{Hb}$ electrophoresis and advised not to go for any blood transfusions in these 3 months. As said, pt came after 3 months with gross pallor, ascites, generalized weakness. We conducted $\mathrm{Hb}$ electrophoresis which was surprisingly normal and did a bone marrow which showed marrow plasmacytosis of $22 \%$, as plasma cell neoplasm are very unlikely and uncommon in this age, serum electrophoresis, calcium, renal function tests, Bence jones protein were done and found to be normal, liver function tests showed elevated liver enzymes and kept a differential diagnosis of Wilson and urinary copper and serum ceruloplasmin was also found to be normal, meanwhile screening for viral markers showed hepatitis B positive, parents too were screened and were found to be negative, viral load was high and plasma cells immunophenotyping showed polyclonal proliferation which might be due to viral hepatitis.

\section{Case 7}

A 29-year-old presented with low back ache to orthopaedics OPD and was kept on some analgesics and muscle relaxants and found to be relieved of the symptoms later presented with joint swelling of right knee with minimal effusion and suspecting inflammatory arthritis found to show all RA ASO found to be negative, CRP mildly elevated and screened for other inflammatory arthritis and auto immune panel which were found to be negative and HLA B 27 also was done and found to be negative, later bone marrow examination was done and showed plasma cells of $43 \%$, serum electrophoresis showed $\mathrm{M}$ spike and diagnosed as case of multiple myeloma. 


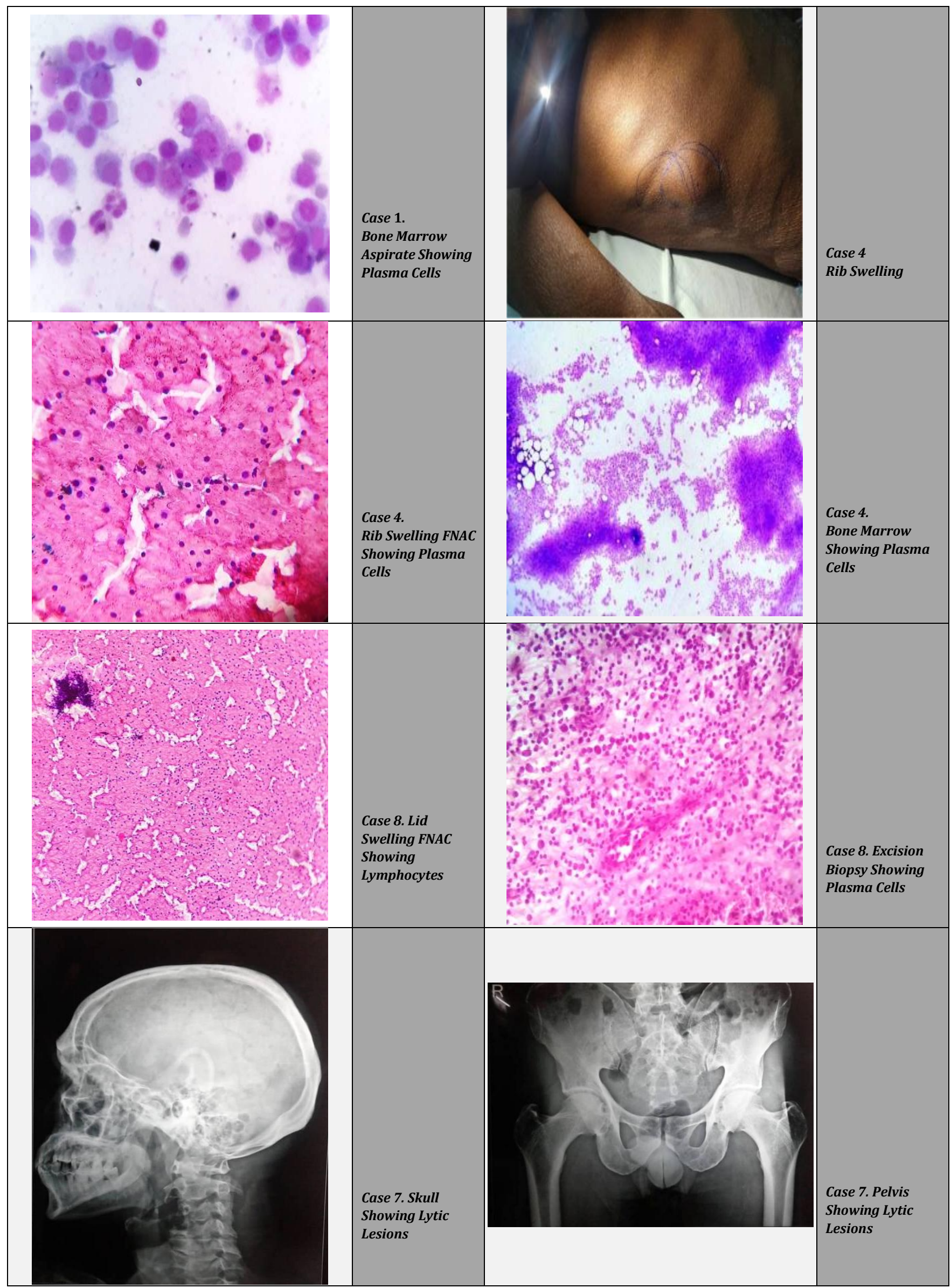




\section{Case 8}

A 40-year-old presented with upper lid swelling to dermatology OPD and advised FNAC which showed lymphocytes and reported as chronic inflammatory lesion and posted for excision and biopsy revealed proliferation of plasma cells and diagnosed as solitary plasmacytoma, patient has not come to collect biopsy report and hence could not be followed up.

\section{Case 9}

A 40-year-old presented with generalized weakness to medicine OPD. On examination patient had severe pallor, hepatosplenomegaly, investigations showed $\mathrm{Hb} 4 \mathrm{gm} \mathrm{\%}$ and total white blood cell TWBC count was 22,000 and platelet count was normal. Peripheral smear showed atypical lymphocytes and bone marrow was done which showed $72 \%$ plasma cells and plasma blasts. Case was reported as plasma cell leukaemia and unfortunately patient has succumbed before diagnosis.

\section{DISCUSSION}

Multiple Myeloma (MM) is categorized as a malignant disorder that targets haematological function in the human body. It presents as the unchecked proliferation of monoclonal / multicentre cells within the bone marrow \& is commonly cited as accounting for over $10 \%$ of malignancies attributed to the presence of haematological disease. ${ }^{1}$ Initially, the patients present asymptomatically.

\section{Case 1 and 2}

Cases 1 and 2 both presented with initial manifestation of bleeding though of different causes and were operated for the specific causes but later postoperative course only found out that these were cases of multiple myeloma, bleeding is generally rare in multiple myeloma, so these cases were missed in the first consultation and also these patients underwent surgical procedures which seem to be initially required but later found out that might not help rather masked the underline marrow pathology. Excessive bleeding is often associated with disease related thrombocytopenia or generalized treatment while thrombosis can be related to paraneoplastic syndromes or treatment with medications like high doses of dexamethasone and derivatives of thalidomide. Acquired von Willebrand disease has been noted in MM and AAL but not in cases of clinically relevant bleeding. Periodic and irregular haemorrhagic events can be attributed to the presence of monoclonal immunoglobulins and manifest in the form of skin haemorrhages to a life-threatening gastrointestinal bleeding. Specific affinity characteristics of the paraprotein with coagulation factors or platelet surface proteins have been established in some cases of severe bleeding associated to a monoclonal gammopathy. ${ }^{11-20}$

\section{Case 3}

Case 3 is found to be very rare presentation of multiple myeloma, similar case have never been reported so far in literature, literature says that coagulation abnormalities may be seen associated with multiple myeloma but this severe and atypical presentation is rare and may be attributed to protein $\mathrm{C}$ and protein $\mathrm{S}$ abnormalities or dysfunction due to paraprotein interfering with the function of coagulation factors. Paraproteinaemias have been linked to thrombotic mechanisms such as hypo fibrinolysis, increased blood viscosity, production of autoantibodies, and the procoagulant effects of inflammatory cytokines or resistance to activated protein C. ${ }^{17-19}$

\section{Case 4}

This case presented with cough, breathlessness and soft tissue mass is generally rare in case of multiple myeloma. A case in 1906 with the patient presenting a palpable rib mass, tangible rib fractures, anaemia, splenomegaly and marked bone pain was the first recorded case of plasma cell leukaemia (PCL).21,22

\section{Case 5}

This case, a known case of diabetic nephropathy with anaemia on erythropoietin therapy suddenly presented as refractory anaemia. Likewise, the symptoms of progressive chronic kidney disease (CKD) are nonspecific, and thus, attending primary care physicians and relevant specialists should consider plasma cell dyscrasia as a viable underlying explanation for patients that showcase a significant variety of presenting complaints.

\section{Case 6}

A rare case of polyclonal plasma cell proliferation due to underlying viral hepatitis presenting with liver failure. Reactive plasmacytosis is a relatively rare occurrence that can be found in a variety of infectious diseases, tumours and autoimmune disorders. ${ }^{23}$ Reactive plasmacytosis has been noted in several types of virus infections including Hepatitis A virus, Epstein-Barr virus, dengue virus, parvovirus B 19.24-27 In this report, we describe two unusual cases of SFTSV (Severe Fever with Thrombocytopenia Syndrome Infection) presenting with reactive plasmacytosis both in peripheral blood and bone marrow.

\section{Case 7}

This patient presented with lid swelling to ophthalmology OPD. Eye abnormalities such as cysts of the ciliary body and vascular lesions have been described in multiple myeloma but primary plasmacytoma involving the eye is rare. Nineteen cases affecting the orbit have been described in the literature but primary plasmacytoma arising from the eyelid is much rare. ${ }^{28}$ Majority of our patients presented with just mild backache without involvement of any bony lytic lesion or any deranged renal profile. This makes the diagnosis difficult. However, as per the International Myeloma Working Group (IMWG) criteria for diagnosis of multiple myeloma, these patients showed presence of one of the myelomas defining events (MDE) (i.e., presence of more than $60 \%$ of plasma cell in bone marrow). In addition, these patients showed decreased haemoglobin level of $<10 \mathrm{gm} / \mathrm{dL}$ as well. 


\section{Case 8}

Our case presented as arthritis here-

The largest series, reported by Jorgensen et al. in 1996, included nine patients with monoclonal gammopathy (MG), either MM or monoclonal gammopathy of uncertain significance, who developed inflammatory chronic arthritis simultaneously or after the diagnosis of MG. Interestingly, all of the patients were seronegative for rheumatoid factor, and the majority had hand and wrist involvement, including two patients who had distal interphalangeal joint involvement not typical of rheumatoid arthritis (RA). ${ }^{29}$

Our case illustrates an atypical presentation of MM mimicking seronegative rheumatoid arthritis, which carried a diagnostic challenge for physicians and caused a delay in the treatment of a life-threatening malignancy. Lack of response to RA treatment should prompt the physician to re-examine the initial diagnosis and think of alternatives. Increased awareness of atypical symptoms for serious diseases such as MM is critically important among health care providers and should become more emphasized in future practice.

\section{Case 9}

Plasma cell leukaemia as such, the incidence itself is rare so included in this study.

\section{CONCLUSIONS}

This present study is a compilation of rare and atypical findings in patients with multiple myeloma. These stress upon the importance of clear and precise clinicopathological correlation to arrive at an exact diagnosis. All cases of refractory anaemias should be followed up with proper peripheral smear and bone marrow examination. However, all patients who present with either back pain, anaemia, renal impairment, hypercalcaemia, age-inappropriate osteopenia, or osteolytic lesions should be screened for the presence of an M-protein. ${ }^{30}$ Early diagnosis and management of such cases can help to decrease the morbidity and mortality and increase the survival chances and initiate early therapy thereby decreasing the complications which can develop earlier or much later in these patients.

Data sharing statement provided by the authors is available with the full text of this article at jemds.com.

Financial or other competing interests: None.

Disclosure forms provided by the authors are available with the full text of this article at jemds.com.

\section{REFERENCES}

[1] Brenner H, Gondos A, Pulte D. Expected long-term survival of patients diagnosed with multiple myeloma in 2006-2010. Haematologica 2009;94(2):270-5.

[2] Kyle RA, Gertz MA, Witzig TE, et al. Review of 1027 patients with newly diagnosed multiple myeloma. Mayo Clin Proc 2003;78(1):21-33.

[3] Jose M, Balan A, Sharafuddeen KP, et al. Mandibular lesion presenting as the first sign of multiple myeloma: a report of two cases. Int J Dent Case Reports 2011;1(2):22-8.
[4] Rajkumar SV, Dimopoulos MA, Palumbo A, et al. International myeloma working group updated criteria for the diagnosis of multiple myeloma. Lancet Oncol 2014;15(12):e538-48.

[5] Short KD, Rajkumar SV, Larson D, et al. Incidence of extramedullary disease in patients with multiple myeloma in the era of novel therapy and the activity of pomalidomide on extramedullarymyeloma. Leukemia 2011;25(6):906-8.

[6] Katzmann JA, Dispenzieri A, Kyle R, et al. Elimination of the need for urine studies in the screening algorithm for monoclonal gammopathies by using serum immunofixation and free light chain assays. Mayo Clin Proc 2006;81(12):1575-8.

[7] Greipp PR, Leong T, Bennett JM, et al. Plasmablastic morphology-an independentprognostic factor with clinical andlaboratory correlates: Eastern Cooperative Oncology Group (ECOG) myeloma trial E9486 report by the ECOG myeloma laboratory group. Blood 1998;91(7):2501-7.

[8] Bartl R, Frisch B, Fateh-Moghadam A, et al. Histologic classification and staging of multiple myeloma. A retrospective and prospective study of 674 cases. Am J Clin Pathol 1987;87(3):342-55.

[9] O'Donnell E, Cottini F, Raje N, et al. Myeloma. Williams Hematology. New York, USA: McGraw-Hill Education 2016.

[10] Rajkumar SV, Kumar S. Multiple myeloma: diagnosis and treatment. Mayo Clin Proc 2016;91(1):101-9.

[11] Lonial S, Waller EK, Richardson PG, et al. Risk factors and kinetics of thrombocytopenia associated with bortezomib for relapsed, refractory multiple myeloma. Blood 2005;106(12):3777-84.

[12] Eby C. Pathogenesis and management of bleeding and thrombosis in plasma cell dyscrasias. Br J Haematol 2009;145(2):151-63.

[13] Coppola A, Tufano A, Di Capua M, et al. Bleeding and thrombosis in multiple myeloma and related plasma cell disorders. Semin Thromb Hemost 2011;37(8):929-45.

[14] Zamagni E, Brioli A, Tacchetti P, et al. Multiple myeloma, venous thromboembolism and treatment-related risk of thrombosis. Semin Thromb Hemost 2011;37(3):209-19.

[15] Uaprasert N, Voorhees PM, Mackman N, et al. Venous thromboembolism in multiple myeloma: current perspectives in pathogenesis. Eur J Cancer 2010;46(10):1790-9.

[16] De Stefano V, Za T, Rossi E. Venous thromboembolism in multiple myeloma. Semin Thromb Hemost 2014;40(3):338-47.

[17] Bagratuni T, Kastritis E, Politou M, et al. Clinical and genetic factors associated with venous thromboembolism in myeloma patients treated with lenalidomide-based regimens. Am J Hematol 2013;88(9):765-70.

[18] Zangari M, Elice F, Fink L, et al. Hemostatic dysfunction in paraproteinemias and amyloidosis. Semin Thromb Hemost 2007;33(4):339-49.

[19] DiMinno G, Coraggio F, Cerbone AM, et al. A myeloma paraprotein with specificity for platelet glycoprotein IIIa in a patient with a fatal bleeding disorder. J Clin Invest 1986;77(1):157-64.

[20] Colwell NS, Tollefsen DM, Blinder MA. Identification of a monoclonal thrombin inhibitor associated with multiple 
myeloma and a severe bleeding order. Br J Haematol 1997;97(1):219-26.

[21] Gluzinski A, Reichentein M. Myeloma I leukaemia lymphatica (plasmocellularis). Wien Klin Wochenschr 1907;19:336.

[22] Van De Donk NWCJ, Lokhorst HM, Anderson KC, et al. How I treat plasma cell leukemia. Blood 2012;120(12):237689.

[23] Pellat-Deceunynck C, Jego G, Robillard N, et al. Reactive plasmacytoses, a model for studying the biology of human plasma cell progenitors and precursors. Hematol J 2000;1(6):362-6.

[24] Thai KTD, Wismeijer JA, Zumpolle C, et al. High incidence of peripheral blood plasmacytosis in patients with dengue virus infection. Clin Microbiol Infect 2011;17(12):1823-8.

[25] Wada T, Maeba H, Ikawa Y, et al. Reactive peripheral blood plasmacytosis in a patient with acute hepatitis A. Int J Hematol 2007;85(3):191-4.
[26] Desborough MJ, Grech H. Epstein-barr virus-driven bone marrow aplasia and plasmacytosis mimicking a plasma cell neoplasm. Br J Haematol 2014;165(3):272.

[27] Koduri PR, Naides SJ. Transient blood plasmacytosis in parvovirus B19 infection: a report of two cases. Ann Hematol 1996;72(1):49-51.

[28] Seddon JM, Corwin JM, Weiter JJ, et al. Solitary extrame dullary plasmacytoma of the palpebral conjunctiva. Br J Ophthalmol 1982;66(7):450-4.

[29] Jorgensen C, Guerin B, Ferrazzi V, et al. Arthritis associated with monoclonal gammapathy: clinical characteristics. Br J Rheumatol 1996;35(3):241-3.

[30] Kyle RA, Buadi FI, Rajkumar SV. Management of monoclonal gammopathy of undetermined significance (MGUS) and smoldering multiple myeloma (SMM). Oncology (Williston Park) 2011;25(7):578-86. 